\title{
Percepção do discente de Medicina sobre a atenção à saúde do imigrante
}

\section{I ${ }^{1}$ Ana Izabel Nascimento Souza, ${ }^{2}$ Halley Ferraro Oliveira |}

Resumo: A migração forçada é um reconhecido determinante social, pois as condiçôes que envolvem o processo migratório tendem a gerar vulnerabilidades e impactos na saúde pública nos países de origem e de destino. O objetivo deste estudo foi a caracterizaçáo sociocultural e a percepção do estudante de Medicina perante imigração, saúde e doença. Realizou-se estudo transversal com estudantes de Medicina em uma instituição de ensino superior do Estado de Sergipe, Brasil, cuja amostra foi composta por 144 alunos regularmente matriculados na instituição. As variáveis foram descritas por meio de frequência absoluta e relativa percentual. As associaçôes entre variáveis categóricas foram testadas por meio de teste Qui-Quadrado de Pearson. As correlaçôes ordinais foram testadas pela correlação gamma. Houve significância em relação à percepção do conhecimento da legislação que garante acesso dos imigrantes aos serviços de saúde ( $\mathrm{p}$-valor $<0,05)$. O perfil sociocultural discente aponta a necessidade de encorajar, no contexto acadêmico, práticas culturais integrativas e habilidades de comunicação, um contributo à formação cidadã e profissional. A Competência Cultural em Saúde se coloca como uma ferramenta que fortalece a tecnologia leve em saúde, a partir do intercâmbio entre profissionais e imigrantes no processo do cuidado em saúde.

> Palavras-chave: competência cultural; saúde; emigração; imigração.

\footnotetext{
${ }^{1}$ Universidade Federal de

Sergipe. São Cristóvão-SE, Brasil (ana_izabelnsouza@hotmail.com). ORCID: 0000-0001-8064-2748

${ }^{2}$ Universidade Federal de Sergipe. São Cristóvão-SE, Brasil (halleyoliveira62@gmail.com). ORCID: 0000-0003-0123-7395
}

Recebido em: 03/10/2019 Aprovado em: 03/03/2020 Revisado em: 09/07/2021 


\section{Introdução}

A mobilidade humana é um fenômeno histórico constitutivo das sociedades, configurado a partir de cenários diferenciados. A complexidade do fluxo migratório contemporâneo atinge "todos os continentes, classes sociais, gêneros, etnias/raças, geraçôes" e as motivaçóes perpassam desde os conflitos armados e políticos a desastres ambientais e busca por melhores condiçôes de vida (VENTURA, 2018).

Pressupóe-se que toda migração é um ato voluntário, porém a noção de migração voluntária é compreendida através dos fluxos econômicos, em razão do aperfeiçoamento profissional e reuniáo familiar. A migração forçada, por sua vez, configura-se como um problema político internacional, pela existência de violências e violaçôes dos direitos humanos que impelem as pessoas a recorrerem à proteção internacional (LIMA, 2017).

A migração forçada é um reconhecido determinante social, pois as condiçóes que envolvem o processo migratório tendem a gerar vulnerabilidades e impactos na saúde pública nos países de origem e de destino. (PEDRERO; BERNALES; PEREZ, 2018). No panorama da migração internacional, as principais categorias de migração forçada são deslocados internos, refugiados, solicitantes de refúgio e apátridas (GRANADA et al., 2017; DIAS; GONÇALVES, 2007).

O Alto Comissariado das Naçóes Unidas para Refugiados (ACNUR) - baseado no Estatuto dos Refugiados criado pela Organização das Nações Unidas em 1951 - atribui a situação de refúgio àqueles que estão fora do país de origem por temores persecutórios relacionados à raça, religião, grupo social, bem como àqueles que foram obrigados a deixar seus países por conflitos armados e graves violações dos direitos humanos (ACNUR, 1951; 2018).

Em seu último Relatório de Tendências Globais, o ACNUR aponta que mais de 70,8 milhôes de pessoas no mundo foram forçadas a saírem de suas casas. Deste total, $58,3 \%$ são deslocados internos; $36,5 \%$ refugiados e $5,2 \%$ solicitantes de refúgio (UNHCR, 2019). Em 2018, o Brasil registrou mais de 172.288 migrantes forçados - a maioria, solicitantes de refúgio, concentrada nos grandes centros urbanos. Em Sergipe, entre 2017 e 2019, houve 36 solicitaçôes de reconhecimento da condição de refugiado por indivíduos oriundos de Afeganistão, Venezuela, Cuba, El Salvador, Marrocos e Suécia (BRASIL, 2019). 
A oportunidade de pluralização da sociedade torna-se aquém do esperado diante do limitado conhecimento legislativo sobre imigração e de sua aplicabilidade por parte dos profissionais de saúde. A equidade em saúde deve ser fomentada a partir de políticas intersetoriais e pela sensibilização profissional à pluralidade e contextos internacionais (PADILHA et al. 2013; DIAS; GONÇALVES, 2007; DANTAS, 2017). A literatura aponta poucas experiências realizadas nas universidades e pouco conhecimento em competência cultural ao final da formação médica. A perspectiva consonante do discente de Medicina em relação às demandas de saúde da população migrante como impacto positivo no cuidado é o pressuposto deste estudo. Objetiva-se avaliar o perfil social e cultural do estudante de Medicina e identificar aspectos que tendem a limitar o conhecimento discente acerca de imigração e sua correlação com a saúde.

A formulação de diversos estudos sobre a saúde do imigrante denota a importância da saúde como um dos principais indicadores de "integração das comunidades não autóctones”, bem como o nível de adequação dos sistemas sanitários dos países que recebem imigrantes e/ou refugiados. (TOPA; NEVES; NOGUEIRA, 2013).

O risco em saúde do imigrante pode ser observado em três instâncias do fenômeno migratório: antes da migração (devido à condição social do país de origem), nas adversidades do deslocamento e na integraçáo aos países de destino - destacando a xenofobia, a precariedade socioeconômica e as barreiras no acesso aos serviços públicos (RODRIGUEZGARCÍA-DE-CORTÁZAR, 2018).

A compreensão sobre cultura torna-se um viés importante para preencher as lacunas da assistência equânime e universal. A formação voltada para as competências culturais coloca-se como uma alternativa importante frente ao despreparo em atuar com populações migrantes - situação que tende a reforçar constrangimentos - e à necessidade de minimizar dificuldades relatadas pelos imigrantes (TOPA; NEVES; NOGUEIRA, 2013).

\section{Métodos}

Trata-se de estudo observacional e transversal com amostra de 144 discentes do curso de Medicina da Universidade Federal de Sergipe entre junho de 2019 e agosto de 2019. O estudo foi submetido à aprovação do comitê de ética em pesquisa da instituição onde fora realizado (CAAE: 11623319.0.0000.5546). A participação no 
estudo foi voluntária, anônima e o consentimento foi obtido através de Termo de Consentimento Livre e Esclarecido.

Foram incluídos todos os discentes que aceitaram participar; excluíram-se os questionários incompletos. A coleta de dados ocorreu mediante questionário autoaplicado, validado (RODRIGUES; DIAS, 2012; DIAS et al., 2011) e adaptado. $\mathrm{O}$ questionário foi dividido entre questôes socioculturais do estudante e questôes relativas a percepçôes sobre saúde, doença e imigração baseadas na escala de concordância tipo Likert, através de dois grupos: discentes do $1^{\mathrm{o}}$ ao $8^{\circ}$ períodos (Grupo Pré-Internato) e discentes do $9^{\circ}$ ao $12^{\circ}$ períodos (Grupo Internato).

As variáveis foram descritas por meio de frequência absoluta e relativa percentual. As associaçôes entre variáveis categóricas foram testadas por meio de teste Qui-Quadrado de Pearson. As correlaçôes ordinais foram testadas pela correlação gamma. O nível de significância adotado é de 5\% e o software utilizado foi o R Core Team 2019.

\section{Resultados}

A amostra foi composta por 144 discentes de Medicina, dos quais 53,4\% eram do sexo masculino. $O$ perfil social (tabela 1) discente indica que $74,3 \%$ são grupo etário de 20 a 25 anos e 52,1\% situam-se no grupo Internato. A cor/etnia predominante é parda $(59,7 \%)$ e a maioria é procedente da zona urbana. Em relação às ocupaçóes extracurriculares, apenas $16,7 \%$ dos alunos exercem algum tipo de atividade remunerada.

O perfil cultural discente (tabela 2) aponta que, além de atividades estudantis e/ou remunerada, os demais discentes ocupam o tempo, preferencialmente, com atividades como leitura $(60,4 \%)$, música $(64,5 \%)$ e cinema (50\%). Em relação ao acesso à Internet, o aluno gasta entre 3 a 5 horas diárias (41\%) entre pesquisas educacionais $(79.8 \%)$, lazer e jogos $(59,7 \%)$. 
Tabela 1. Perfil Social do Discente de Medicina, Aracaju-SE, 2019

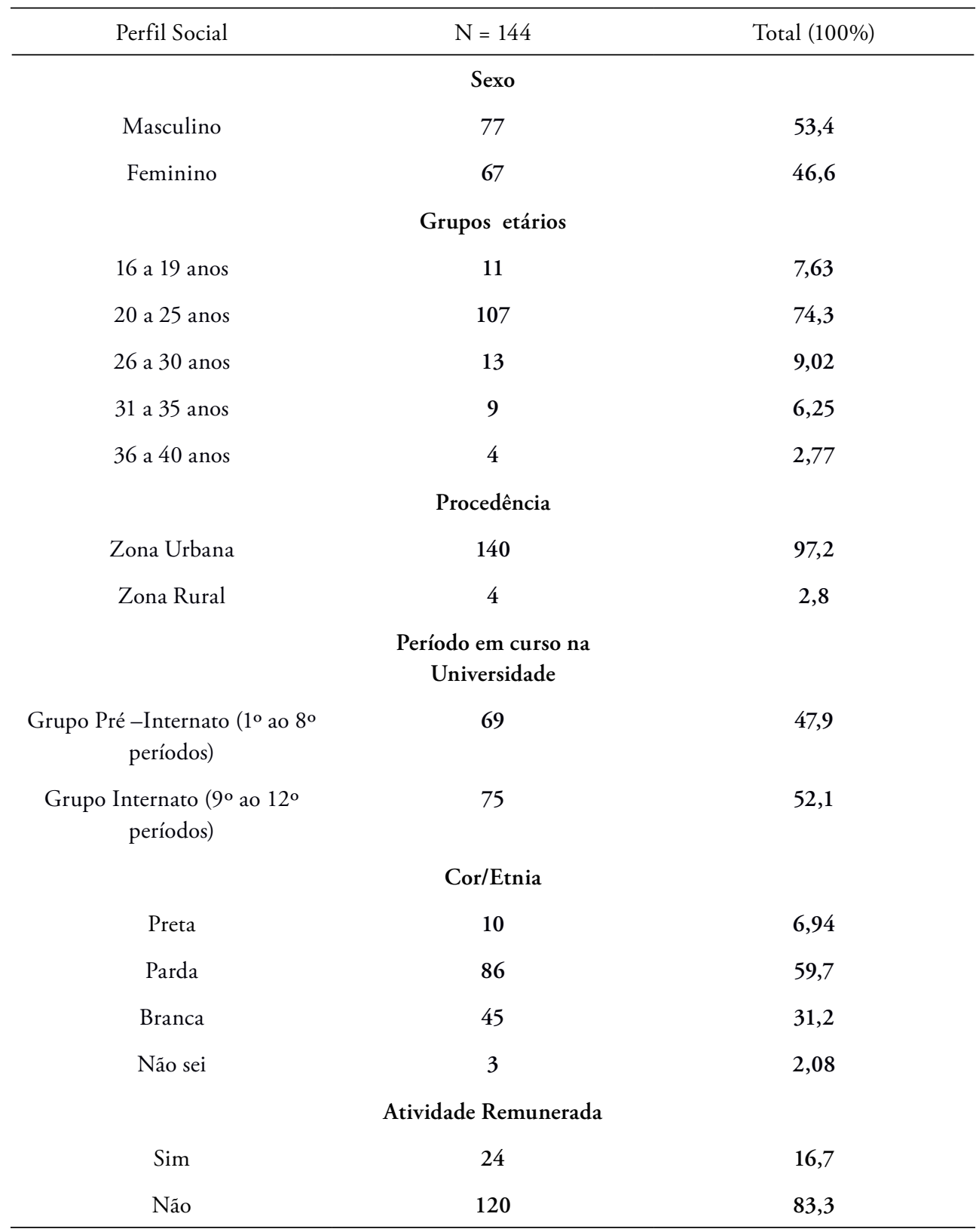


Tabela 2. Perfil Cultural do Discente de Medicina, Aracaju-SE, 2019.

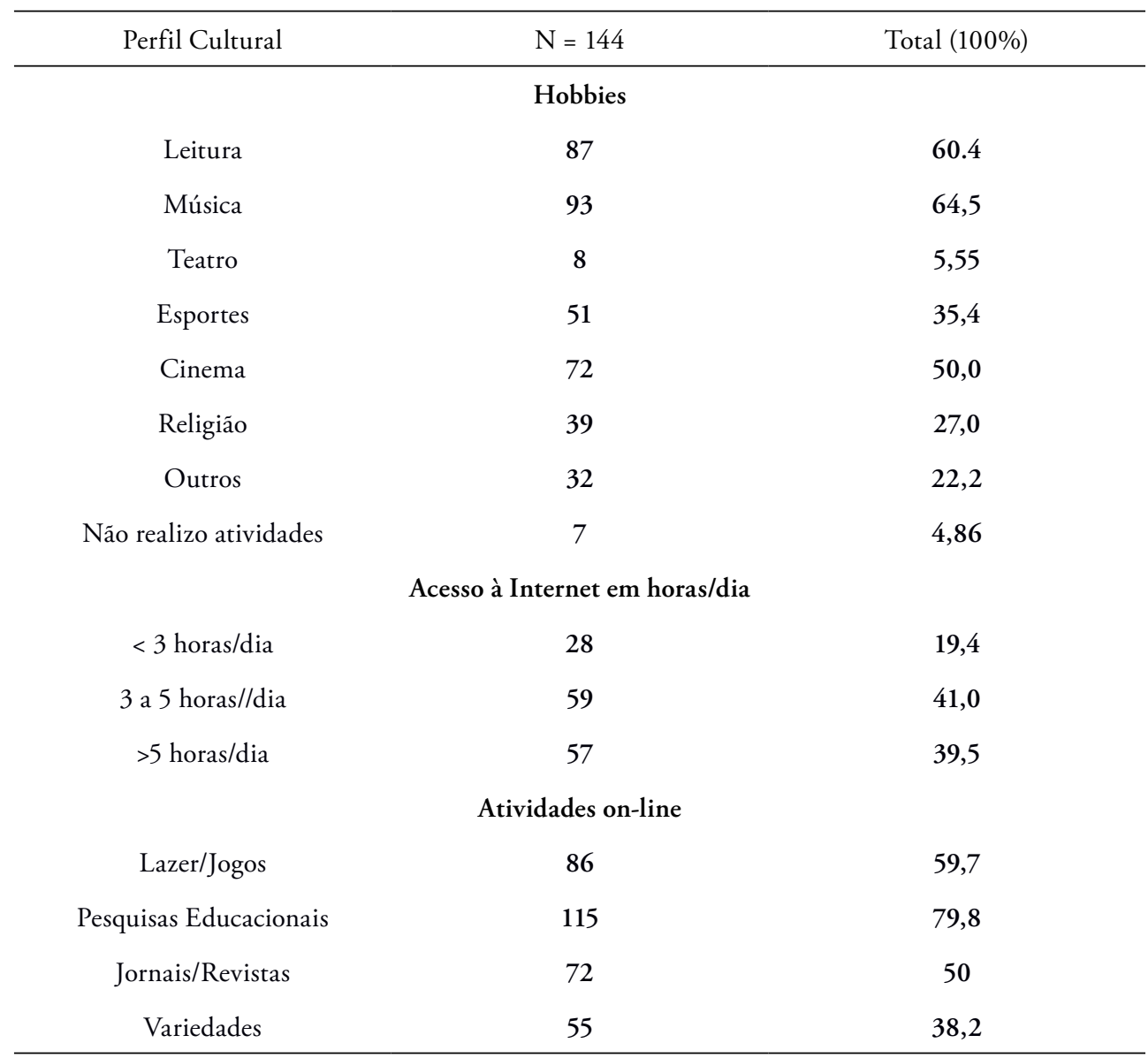

Quanto à percepção do estudante relativa aos conhecimentos em imigração, saúde e doença, os dois grupos consideram que sociedades que acolhem imigrantes tornam-se mais solidárias e culturalmente ricas e concordam que os imigrantes são importantes contribuintes na economia e desenvolvimento do país (tabela 3).

Observou-se que nos dois grupos estudados, o aumento do número de imigrantes no Brasil não configura uma ameaça ao país (tabela 3). A interpretaçáo do estado de saúde imigrante como dependente da integração com o país de acolhimento foi predominante no grupo Pré-Internato $(92,7 \%)$ em relação ao grupo Internato (84,0\%). A relação entre o aparecimento de doenças em virtude da imigração obteve maior concordância no grupo Internato (80\%). 
A percepção de que as doenças nos imigrantes configuram um perigo à saúde pública foi prevalente entre os discentes do grupo Internato (65,3\%). Quanto aos conhecimentos e competências para lidar com o imigrante, os discentes do grupo PréInternato autoanalisaram-se como ruins em 53,6\% e o grupo Internato considerouse razoável $(52,0 \%)$. Cerca de dois terços dos alunos abordados no estudo $(86,8 \%)$ indicaram desconhecimento em relação à legislação que assegure direitos aos imigrantes o acesso aos serviços de saúde. A relevância de uma formação específica sobre saúde do imigrante foi considerada importante nos dois grupos estudados (tabela 3).

A associação entre autoavaliação das competências discentes e percepção de imigração, saúde e doença através do Teste Qui-quadrado de Pearson (tabela 4) permitiu avaliar que a correlação das variáveis foi significativa apenas em relação à percepção do conhecimento da legislaçáo que garante acesso dos imigrantes aos serviços de saúde ( $\mathrm{p}$-valor $<0,05$ ).

Tabela 3. Percepção do Discente de Medicina sobre Imigração, Saúde e Doença por Grupos de estudo, Aracaju-SE, 2019

\begin{tabular}{lll}
\hline \multirow{2}{*}{ Percepçáo sobre Imigração, Saúde e Doença } & Pré-Internato & Internato \\
\cline { 2 - 3 } & $\mathrm{n}=69(47,9 \%)$ & $\mathrm{n}=75(52,1 \%)$ \\
\hline
\end{tabular}

As sociedades que acolhem os imigrantes tornam-se mais solidárias e culturalmente ricas?

\section{Concordo}

Nem Concordo nem Discordo

Discordo

Imigrantes são importantes porque contribuem para a

economia e desenvolvimento do país?

$$
\text { Concordo }
$$

Nem Concordo nem Discordo

Discordo

O aumento do número de imigrantes no Brasil pode ser uma ameaça para o país?

$\begin{array}{cc}62(89,9 \%) & 67(89,4 \%) \\ 7(10,1 \%) & 7(9,3 \%) \\ 0 & 1(1,3 \%)\end{array}$

$40(58,0 \%) \quad 38(50,7 \%)$

$27(39,1 \%) \quad 34(45,3 \%)$

$2(2,9 \%) \quad 3(4,0 \%)$
Concordo
Nem Concordo nem Discordo
Discordo
$9(13,0 \%)$
$6(8,0 \%)$
$20(29,0 \%)$
$29(38,7 \%)$
$40(58,0 \%)$
$40(53,3 \%)$
continua... 


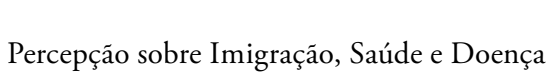

\begin{tabular}{cc} 
Pré-Internato & Internato \\
\hline $\mathrm{n}=69(47,9 \%)$ & $\mathrm{n}=75(52,1 \%)$
\end{tabular}

O estado de saúde dos imigrantes depende da sua integraçáo no país de acolhimento?

$$
\text { Concordo }
$$

Nem Concordo nem Discordo

Discordo

A imigraçáo acarreta dificuldades que potencializam o aparecimento de doenças?

$$
\text { Concordo }
$$

Nem Concordo nem Discordo

Discordo

As doenças nos imigrantes são um perigo para a saúde pública?

$$
\text { Concordo }
$$

Nem Concordo nem Discordo

Discordo

Autoavaliaçáo dos conhecimentos e competências para lidar com imigrantes?

$$
\begin{gathered}
\text { Ruim } \\
\text { Razoável } \\
\text { Boa }
\end{gathered}
$$

Como é sua percepção do conhecimento da legislação do acesso dos imigrantes aos serviços de saúde?

$$
\begin{gathered}
\text { Desconheço } \\
\text { Conheço } \\
\text { Conheço muito bem }
\end{gathered}
$$

Há relevância em receber formação específica sobre a saúde dos imigrantes?

$$
\text { Concordo }
$$

Nem Concordo nem Discordo

$$
\begin{array}{cc}
64(92,7 \%) & 63(84,0 \%) \\
3(4,3 \%) & 6(8,0 \%) \\
2(2,9 \%) & 6(8,0 \%)
\end{array}
$$

$\begin{array}{cc}48(69,5 \%) & 60(80,0 \%) \\ 16(23,2 \%) & 12(16,0 \%) \\ 5(7,3 \%) & 3(4,0 \%)\end{array}$

$37(53,6 \%) \quad 49(65,4 \%)$

$19(27,6 \%) \quad 13(17,3 \%)$

$13(18,8 \%) \quad 13(17,3 \%)$

$\begin{array}{cc}61(88,4 \%) & 64(85,4 \%) \\ 8(11,6 \%) & 10(13,3 \%) \\ 0 & 1(1,33 \%)\end{array}$

$54(78,2 \%) \quad 55(73,4 \%)$

$13(18,8 \%) \quad 16(21,3 \%)$

Discordo

0

$4(5,33 \%)$ 
Tabela 4. Autoavaliação Discente e Percepção sobre Imigração, Saúde e Doença, AracajuSE, 2019

\begin{tabular}{|c|c|c|c|c|c|}
\hline & \multicolumn{3}{|c|}{$\begin{array}{c}\text { Autoavaliaçáo dos conhecimentos } \\
\text { e competências para lidar com } \\
\text { imigrantes }\end{array}$} & \multirow[b]{2}{*}{ p-valor } & \multirow[b]{2}{*}{$\gamma(\mathrm{p}$-valor $)$} \\
\hline & $\begin{array}{l}\text { Ruim } \\
\text { n (\%) }\end{array}$ & $\begin{array}{l}\text { Razoável } \\
\text { n (\%) }\end{array}$ & $\begin{array}{c}\text { Boa } \\
\mathrm{n}(\%)\end{array}$ & & \\
\hline \multicolumn{6}{|l|}{$\begin{array}{l}\text { As doenças nos imigrantes são } \\
\text { um perigo para a saúde pública? }\end{array}$} \\
\hline Discordo & $12(17,6)$ & $12(16,9)$ & $2(40)$ & 0,443 & $-0,1(0,48)$ \\
\hline Nem concordo nem discordo & $13(19,1)$ & $19(26,8)$ & $0(0)$ & & \\
\hline Concordo & $43(63,2)$ & $40(56,3)$ & $3(60)$ & & \\
\hline \multicolumn{6}{|l|}{$\begin{array}{l}\text { Como é sua percepção do } \\
\text { conhecimento da legislação } \\
\text { do acesso dos imigrantes aos } \\
\text { serviços de saúde? }\end{array}$} \\
\hline Desconheço & $63(92,6)$ & $59(83,1)$ & $3(60)$ & $<0,001$ & $0,49(0,033)$ \\
\hline Conheço & $5(7,4)$ & $12(16,9)$ & $1(20)$ & & \\
\hline Conheço muito bem & $0(0)$ & $0(0)$ & $1(20)$ & & \\
\hline \multicolumn{6}{|l|}{$\begin{array}{l}\text { Há relevância em receber } \\
\text { formaçáo específica sobre a saúde } \\
\text { dos imigrantes? }\end{array}$} \\
\hline \multicolumn{6}{|l|}{ Discordo } \\
\hline & $2(2,9)$ & $2(2,8)$ & $0(0)$ & 0,173 & $-0,26(0,134)$ \\
\hline Nem concordo nem discordo & $9(13,2)$ & $20(28,2)$ & $0(0)$ & & \\
\hline Concordo & $57(83,8)$ & $49(69)$ & $5(100)$ & & \\
\hline
\end{tabular}

Legenda: $\mathrm{n}$ - frequência absoluta. \% - frequência relativa percentual. $\gamma$ - correlação Gamma. Teste Quiquadrado de Pearson.

\section{Discussão}

O presente estudo pretendeu conhecer o perfil social e cultural do discente de Medicina e suas perspectivas sobre imigração, saúde e doença. De modo geral, podese observar que o estudante de Medicina apresenta um perfil que favorece o contato cultural e dispóe de ferramentas viáveis para a construção de competências para lidar com imigrantes. 
Esse perfil social preponderante de discentes jovens e concludentes do curso que dispóem de meios educacionais e culturais diversos contrasta com a insipiência sobre as garantias legais do acesso à saúde por grupos migrantes. A autoavaliação discente perante os conhecimentos e competências reforça a necessidade de abordar competências culturais para lidar com especificidades em saúde (DIAS, 2011).

A interface entre dinâmica migratória e estado de saúde - percebida pela maioria dos discentes - é apontada como reflexo das circunstâncias de exclusão e instabilidade sociais, mas que possuem riscos semelhantes à população autóctone (RODRIGUES; DIAS, 2012). Entretanto, aponta Padilha (2013) que esses riscos dependem das características desses grupos populacionais - a exemplo de padróes de mortalidade, doenças e utilização dos serviços de saúde permeados pela baixa procura de cuidados preventivos e a superlotação de urgências.

Trata-se um circulo vicioso de exclusão, vulnerabilidade e doença através do condicionamento negativo do imigrante na sociedade de destino. Tal dinâmica acaba sendo reforçada pela coexistência de relaçôes assimétricas entre médicos e pacientes, gerando uma prática clínica cultural frustrada, uma vez que não há referência nosológica comum (RODRIGUES; DIAS, 2012; PADILHA, 2013; SILVEIRA; GOLDBERG; COVIELLO, 2018).

Face à percepção geral da imigração, os discentes compreendem o fenômeno migratório como fator social relevante. Contudo, a maior parte dos participantes considera o aumento do número de imigrantes uma ameaça para o país, o que demonstra a consonância descrita por parte dos profissionais de saúde (RODRIGUES; DIAS, 2012).

A percepção de ameaça em relação ao imigrante é, predominantemente, em sentido econômico - competitividade no mercado de trabalho, sobretudo com imigrantes de origem asiática, europeia e norte-americana -, seguida da percepção de ameaça simbólica e da ameaça de segurança (GONDIM, 2013). A percepção de que os imigrantes representam uma ameaça à saúde pública por serem potenciais transmissores de doenças, como apontam Rodrigues e Dias (2012), torna-se um fator discriminatório e estigmatizante que se reflete no acesso aos serviços de saúde.

Há necessidade de adequação ao aumento das demandas de saúde para indivíduos culturalmente distintos. O contexto acadêmico deve encorajar práticas culturais integrativas e habilidades de comunicação, contribuindo na formação cidadã e profissional. $\mathrm{O}$ acesso à Internet é apontado como uma ferramenta para 
compreender os transtornos de saúde a partir da produçáo cientifica internacional, a fim de enriquecer os conhecimentos de alunos, professores e profissionais de saúde (GOULART; LEVEY; RECH, 2018).

A Universidade assume papel relevante na criação de açóes que atendam às exigências sociais. Entretanto, profissionais de saúde não apresentam formação orientada para habilidades básicas nos cuidados multiculturais, demonstrando, assim, a necessidade de atualização dos modelos curriculares coerentes com as demandas globais (RODRIGUEZ-MARTIN, 2015; ALIAGA, 2017).

A Competência Cultural em Saúde assume o papel de fortalecer a tecnologia leve em saúde, a partir do intercambio bidirecional do cuidado. Enfatiza-se, então, o desafio de reposicionamentos epistemológicos, metodológicos e éticos para a construção dos "cuidados de saúde culturalmente adaptados" (RODRIGUEZMARTIN, 2015; GONÇAVES; MATOS, 2016; RAMOS, 2017).

Tendo em vista a existência de políticas de assistência ao refugiado em âmbito nacional, o desconhecimento de leis e garantias por parte da equipe de saúde sinaliza o desafio, segundo Silveira, Golderberg e Coviello (2018, p. 99), do "desenvolvimento da cidadania social com relação ao corpo e à doença" no intuito de evitar a "patologização do corpo migrante".

Os resultados obtidos devem ser interpretados considerando as limitações quantitativas na aplicação dos questionários devido à representatividade da amostra ( $24 \%$ do total de alunos da instituição). No entanto, a relevância dos dados sobre a importância de uma formação específica sobre saúde do imigrante e a correlação observada entre autoavaliaçáo de competência e conhecimento sobre legislaçáo de acesso aos serviços de saúde configuram pontos de destaque deste estudo.

A partir de estudos com profissionais de saúde, buscou-se analisar o perfil discente, sendo pertinente, destarte, formular novas investigaçóes voltadas - de modo específico - ao âmbito acadêmico para aprofundar as perspectivas do ensino culturalmente competente.

\section{Conclusão}

A percepção do discente de Medicina sobre a saúde do imigrante demonstra a possibilidade de utilização de ferramentas do cotidiano para estímulo e formação cultural. A proposta de capacitação de profissionais de saúde, a partir das competências 
culturais, permite adequar a prática clínica às necessidades de saúde dos imigrantes e refugiados, além de reduzir vulnerabilidades e barreiras do cuidado. ${ }^{1}$

\section{Referências}

UNHCR. United Nations High Commissioner for Refugees. Global Trends - Forced Displacement in 2019. Disponível em: <https://www.unhcr.org/globaltrends2018/\#_ ga=2.87427480.1628786108.1579825957-1888937035.1553646137>. Acesso em: 23 jan. 2020 .

ACNUR. Alto comissariado das Naçóes Unidas para refugiados. Convenção Relativa ao Estatuto dos Refugiados. 1951. Disponível em: <https://www.acnur.org/fileadmin/Documentos/portugues/ BDL/Convencao_relativa_ao_Estatuto_dos_Refugiados.pdf >. Acesso em: 16 jan. 2020.

ALIAGA, J. D. J.et al. La multiculturalidad como enfoque para la educación médica superior. Multimed. v. 19, n. 1, 2017. Disponível em: <http://www.revmultimed.sld.cu/index.php/mtm/ article/view/477>. Acesso em: 18 abr. 2019.

BRASIL. Ministério da Justiça e Segurança Pública. 1990 a 2019: solicitaçóes de reconhecimento da condição de refugiado. Disponível em: <https:/www.justica.gov.br/seusdireitos/refugio/ anexos/1990-a-2019-solicitacoes-de-reconhecimento-da-condicao-derefugiado.xlsx/view>. Acesso em: 26 maio 2019.

DIAS, S. et al. Barreiras no acesso e utilização dos serviços de saúde pelos imigrantes: A Perspectiva dos Profissionais de Saúde. Acta Med Port., v. 24, n. 4, p. 511-516, 2011. Disponível em: <https://www.actamedicaportuguesa.com/revista/index.php/amp/issue/view/17>. Acesso em: 24 mar. 2019.

GONDIM, S. M. G. et al. Imigração e Trabalho: Um Estudo Sobre Identidade Social, Emoções e Discriminação Contra Estrangeiros. Psicol. pesq. Juiz de Fora, v. 7, n. 2, p. 151-163, 2013. Disponível em: <http://pepsic.bvsalud.org/scielo.php?script=sci_arttext\&pid=S1982$12472013000200003 \& \operatorname{lng}=$ pt\&nrm=iso $>$. Acesso em: 29 abr. 2019

GONÇALVES, M.; MATOS, M. Competência Cultural na Intervenção com Imigrantes: Uma Análise Comparativa entre Profissionais da Saúde, da Área Social e Polícias. Acta Med Port., v. 29, n. 10, p. 629-638, 2016. Disponível em: <https://www.actamedicaportuguesa.com/revista/ index.php/amp/article/view/7121>. Acesso em: 10 abr. 2019.

GOULART, B. G.; LEVEY, S.; RECH, R. S. Competências em multiculturalismo, assistência à saúde e transtornos de comunicação. Cadernos de Saúde Pública, v. 34, n. 4, 2018. Disponível em: <https://scielosp.org/pdf/csp/2018.v34n4/e00217217/en>. Acesso em: 10 abr. 2019.

PADILHA, B. Saúde dos imigrantes: multidimensionalidade, desigualdades e acessibilidade em Portugal. Rev. Inter. Mob. Hum. Brasília, ano XXI, n. 40, p. 49-68, jan./jun. 2013. Disponível em: >http://www.scielo.br/pdf/remhu/v21n40/04.pdf>. Acesso em: 26 ago. 2019. 
PEDRERO, V.; BERNALES, M.; PÉREZ, C. Migración y competencia cultural: un desafío para los trabajadores de salud. Rev. Med. Clin. Condes, v. 29, n. 3, p. 353-359, 2018. Disponível em: <https://reader.elsevier.com/reader/sd/pii/S0716864018300658?token=95E5CFA9CF18FC 1FF459989CC57BCB2EA1ABF63962ABCBEE732A4F45B5E2C4D54525758326012D6530 3869B1F97084F>. Acesso em: 20 abr. 2019.

RAMOS, N. Comunicação em saúde, interculturalidade e competências: desafios para melhor comunicar e intervir na diversidade cultural em saúde. In: RANGEL, M. L.; RAMOS, N. (Org.). Comunicaçâo e saúde: perspectivas contemporâneas. Salvador: EDUFBA, 2017. p. 149-172. RODRIGUES, R.; DIAS, S. Encontro com a diferença: a perspectiva dos profissionais de saúde no contexto da prestação de cuidados aos imigrantes. Forum Sociológico [on-line], v. 22, 2012. Disponível em: <https://journals.openedition.org/sociologico/583\#quotation>. Acesso em: 25 mar. 2019.

RODRÍGUEZ-GARCÍA-DE-CORTÁZAR, A. et al. Salud Pública (también) para las personas migrantes y refugiadas en Europa. Gaceta Sanitaria. Granada, Espanha. v. 32, p. 111-113, 2018. Disponível em: <https://reader.elsevier.com/reader/sd/pii/S0213911117301413?token=8D4138 564F6483A512B9E51F5165F499ECAB7D947C04BD2C80EF44FE07BAA3CA7C0C88634 B7AF73C8EE7E9196DEF19C3>. Acesso em: 20 abr. 2019.

RODRIGUEZ-MARTIN, B. Desafíos y oportunidades de las situaciones de contacto cultural en el ámbito sanitario. Index Enferm. Granada, v. 24, n. 4, p. 227-231, 2015. Disponível em: $<$ http://scielo.isciii.es/scielo.php?script=sci_arttext\&pid=S1132-12962015000300008\&lng=es \&nrm=iso>. Acesso em: 19 abr. 2019.

SILVEIRA, C.; GOLDBERG, A.; COVIELLO, D. M. (Org.). Migração, refúgio e saúde. Santos: Editora Leopoldianum, v. 1, p. 181-191, 2018.

TOPA, J.; NEVES, S.; NOGUEIRA, C. Imigração e saúde: a (in)acessibilidade das mulheres imigrantes aos cuidados de saúde. Saúde e sociedade. São Paulo, v. 22, n. 2, p. 328-341, 2013. Disponível em: <http://www.scielo.br/scielo.php?script=sci_arttext\&pid=S0104$12902013000200006 \& \operatorname{lng}=e n \&$ nrm=iso>. Acesso em: 20 abr. 2019.

\section{Nota}

${ }^{1}$ A. I. N. Souza: conceituação, seleção de dados, análise formal, investigação, metodologia; redação, revisão e edição do artigo. H. F. Oliveira: análise formal, metodologia, supervisão, redação e revisão do artigo. 


\section{Abstract}

\section{Perception of medical students about immigrant's healthcare}

Forced migration is a recognized social determinant, because the conditions surrounding the migratory process tend to generate vulnerabilities and impacts on the public health on the countries of origin and destination. This study focused on the socio-cultural characterization and the perception of the medical student about immigration, health and disease. A cross-sectional study was carried out with medical students at a higher education institution of the State of Sergipe, Brazil. The study sample consisted of 144 students who were regularly enrolled in the institution. The variables were described by means of absolute frequency and relative percentage. The associations between categorical variables were tested using Pearson's chi-squared test. The ordinal correlations were tested by the gamma correlation, there was significance in relation to the perception of the knowledge of the legislation guaranteeing immigrant access to health services (P-value $<0.05)$. The student socio-cultural profile points to the need to encourage, in the academic context, integrative cultural practices and communication skills a contribution to citizen and professional training. The Cultural Competence in Health stands as a tool that strengthens light technology in health, from the exchange between professionals and immigrants in the health care process.

Keywords: immigration; health; cultural competence. 